\title{
Acute intoxication with ethanol and medicines - a new combination in the ethiology of child intoxications
}

\author{
Intoxicaţia acută cu etanol şi medicamente - o combinaţie nouă în etiologia \\ intoxicaţiilor la copil
}

\begin{abstract}
Cătălin Corneliu Stemate, Coriolan Emil UImeanu
Spitalul Clinic de Urgenţă pentru Copii „Grigore Alexandrescu“, Bucureşti, România

ABSTRACT

Ethanol intoxications are frequent in children, due to the ubiquitous presence of this substance and can result in serious metabolic phenomena, with important, often irreversible sequelae.

Starting from the incidence and the severe forms of acute ethyl alcohol intoxication in children, we conducted a trial that focused on voluntary acute ethyl alcohol intoxications associated with drugs in patients hospital-ized in a pediatric toxicology centre between 2005 and 2009.

The association ethyl alcohol-drugs or psychoactive substances occured in $10 \%$ of the severe ethyl alcohol intoxications in teenagers, increasing the severity of intoxication, the depth of the coma and the length of hospitalization.

Keywords: ethyl alcohol, substances of abuse, teenager, drugs

\section{REZUMAT}

Intoxicaţiile cu alcool etilic sunt frecvente la copil din cauza prezenţei ubicuitare a acestei substanţe şi pot produce fenomene metabolice grave cu sechele importante, adesea ireversibile.

Plecând de la frecvenţa şi de la formele grave de intoxicaţie acută cu alcool etilic la copil, am efectuat un studiu care s-a axat pe intoxicaţiile acute voluntare cu alcool etilic în asociere cu medicamente internate întrun centru de toxicologie pediatrică între anii 2005 şi 2009.

Asocierea alcool etilic - medicamente sau substanţe de abuz a fost întâlnită în $10 \%$ dintre intoxicaţiile grave cu alcool etilic la adolescenţi, această asociere determinând creşterea severităţii intoxicaţiei, a profunzimii comei şi a duratei de spitalizare.
\end{abstract}

Cuvinte cheie: alcool etilic, substanţe de abuz, adolescent, medicamente

\section{INTRODUCERE}

Alcoolii din care face parte şi alcoolul etilic sunt hidrocarburi care conțin o grupare hidroxil $(-\mathrm{OH})$ pe un carbon terminal (etanol, metanol) sau la nivelul unui carbon, legat cu alți 2 atomi de carbon (izopropanol) (1).

Intoxicaţiile cu alcool etilic sunt frecvente la copil din cauza prezenței ubicuitare a acestei substanțe (2).

La copil, intoxicațiile cu alcool etilic pot produce fenomene metabolice grave cu sechele importante, adesea ireversibile.
Prevalența intoxicației cu alcool etilic este în creştere. Astfel, dintr-un total de 74.317 cazuri de intoxicație cu etanol sau etilenglicol raportate de Asociația Americană a Centrelor Antitoxice în 2002, 28.077 cazuri (38\%) au fost la adolescenți sub 19 ani (2). În România, există aproximativ 24.000 cazuri de intoxicații cu alcool la adolescenții sub 19 ani.

\section{Etiologie}

Intoxicația cu alcool etilic poate apărea după ingestia de băuturi alcoolizate, cum ar fi băuturi spirtoase (tari), vin, bere, băuturi alcoolice domestice 
(țuică, vişinată etc.), dar şi după ingestie de produse domestice (parfumuri, gargarisme, loțiuni după ras) (2).

\section{Farmacologie}

Uzual, alcoolul etilic se absoarbe în proporție de 80-90\% în 30-60 minute, alimentele putând însă întârzia absorbția la 4-6 ore (4).

La copil, doza toxică de etanol este de $1 \mathrm{~g} / \mathrm{kg}$ corp, iar doza potențial letală este de $3 \mathrm{~g} / \mathrm{kg}$ corp $(1,2)$. La adult, doza letală este de $5-8 \mathrm{~g} / \mathrm{kg}$ corp $(3,4)$.

$\mathrm{O}$ cantitate de $30 \mathrm{ml}$ băuturi spirtoase, $150 \mathrm{ml}$ vin sau $360 \mathrm{ml}$ bere conține $15 \mathrm{~g}$ etanol pur (2).

Concentrațiile serice toxice de etanol la copil sunt de peste $22 \mathrm{mmol} / 1 \mathrm{sau}$ peste $100 \mathrm{mg} / \mathrm{dl}(1,2)$.

\section{Fiziopatologie}

Acțiunea toxică principală a etanolului se produce la nivelul sistemului nervos central:

- primele manifestări sunt de stimulare neuropsihică: euforie şi pierderea inhibiţiei, tulburări de comportament ca urmare a depresiei centrilor de control cerebrali (la niveluri serice de 5-10 mmol/1 sau 23-46 mg/dl) (2);

- printre primele manifestări ale efectului depresor al etanolului asupra cortexului cerebral sunt alterarea judecăţii şi diminuarea capacitătii de concentrare (la niveluri serice de 10-20 mmol/1 sau 46-91 mg/dl) (2);

- creşterea concentrației sangvine de etanol produce depresie generalizată a activităţii SNC cu atonie şi sedare extremă (la concentrații de 20-40 mmol/1 sau 91-182 mg/dl) (2);

- coma profundă este indusă la concentrații serice de peste $40 \mathrm{mmol} / 1 \mathrm{sau} 182 \mathrm{mg} / \mathrm{dl}$ şi se asociază cu pierderea reflexelor de protecție a căilor aeriene superioare și depresia centrilor respiratori, hipotermie, hipoglicemie severă şi cu deces (la concentrații de peste 80 $\mathrm{mmol} / \mathrm{l}$ sau $364 \mathrm{mg} / \mathrm{dl}$ ) (2).

Mecanismele biologice responsabile de aceste efecte sunt plurifactoriale şi nu au fost pe deplin elucidate. Etanolul interferă cu activitatea receptorilor MMDA (M-metil D-aspartat) şi cu activitatea receptorilor GABA (acid $\gamma$-aminobutiric). Efectul sedativ produs de alcool se datorează inhibiției efectului excitator al receptorilor MMDA, combinat cu potențarea efectului inhibitor al receptorilor $\operatorname{GABA}(1,2)$.

Etanolul are şi efecte metabolice: blocajul formării de glicogen hepatic (induce hipoglicemie şi convulsii la copiii şi adolescenții fără rezerve de glicogen), diminuarea sintezelor proteice, creşterea sintezei hepatice de acizi graşi liberi, acidoză metabolică prin acumulare de lactat, hipomagnezemie, gaură osmolară de $10 \mathrm{mosm} / \mathrm{kg} \mathrm{H}_{2} \mathrm{O}$.

\section{DIAGNOSTIC}

Alterarea stării de conştiență (la care se poate adăuga halena etilică specifică) este semnul principal într-o intoxicație cu alcool etilic, iar diagnosticul clinic este confirmat paraclinic prin determinarea concentrațiilor sangvine (2).

\section{TABLOU CLINIC}

Manifestările clinice apar rapid după ingestia accidentală sau voluntară de alcool etilic. Semnele clinice sunt reprezentate iniţial de euforie, agitaţie neuropsihică şi mers ebrios (incoordonare motorie). Dacă nu se intervine terapeutic, evoluția este gravă la copil, asociind hipotonie, letargie şi comă. Ulterior, în evoluție, pot să apară hipotensiune arterială, hipotermie şi tulburări respiratorii severe (2).

La copilul de vârstă mică, prognosticul este grav dacă sunt prezente comă cu depresie respiratorie şi hipoglicemie prelungită.

La copilul mare şi la adolescent, intoxicaţia poate evolua în 3 faze:

1. Faza excitomotorie: tulburări de comportament, logoree, dezinhibiție profundă. Această fază căutată de pacient se poate însoți de o scădere a senzoriului şi a nocicepţiei;

2. Faza de încordare: tulburări de vorbire, logoree mai ales, tulburări senzoriale importante, cu halucinaţii vizuale şi auditive, scăderea netă a pragului la durere, sindrom cerebelos, sindrom vestibular cu vertij şi nistagmus, convulsii;

3. Coma alcoolică: este o comă calmă, cu hipotonie şi reflexe diminuate, fără semne de localizare (5).

\section{Paraclinic}

Paraclinic, în afară de alcoolemie, este necesară monitorizarea glicemiei şi a echilibrului acido-bazic.

\section{COMPLICATIII}

Complicațiile specifice intoxicației cu etanol pot fi:

- nespecifice (comune tuturor comelor) - insuficiență respiratorie acută, pneumonie de inhalație, rabdomioliză de postură, hipotermie 
- specifice - convulsii, unele colapsuri, acidocetoza alcoolică şi complicații digestive. La copil, este foarte importantă hipoglicemia prelungită, asociată sau nu cu convulsii (5).

\section{TRATAMENT}

Intoxicaţia cu alcool etilic este o urgență în toxicologia pediatrică. Copilul va fí internat şi monitorizat cel puțin 24 ore (1).

a) Pacient instabil

- cu insuficiență respiratorie acută sau iminentă: intubație orotraheală (2);

- cu alterarea severă a stării de conştiență: imobilizarea coloanei vertebrale cervicale, intubație orotraheală dacă scorul de comă Glasgow pediatric $(\mathrm{PGCS})<8$, tratamentul convulsiilor (2).

b) Pacient stabil

- decontaminare gastrointestinală - nu se administrează cărbune activat sau sirop de ipeca (decât dacă ingestia de alcool este asociată cu ingestia altor substanțe) (1).

- tratament suportiv şi simptomatic: reechilibrare hidroelectrolitică (perfuzie cu glucoză şi electroliți), corectarea acidozei, tratamentul vărsăturilor (cu metoclopramid sau ondasetron) (1).

- epurarea extrarenală: hemodializa este tehnica indicată în intoxicația acută cu alcool etilic în caz de instabilitate hemodinamică sau de alcoolemie de peste $400 \mathrm{mg} / \mathrm{dl}$ (1).

\section{STUDIU CLINIC}

\section{Obiectivele studiului}

Plecând de la frecvența şi de la formele grave de intoxicație acută cu alcool etilic la copil, studiul efectuat s-a axat pe intoxicațiile acute voluntare $\mathrm{cu}$ alcool etilic în asociere cu medicamente internate într-un centru de toxicologie pediatrică între 2005 şi 2009.

\section{Material şi metode}

S-a realizat un studiu retrospectiv comparând cazurile internate de intoxicații acute voluntare cu alcool etilic şi intoxicații acute voluntare cu alcool etilic în asociere cu medicamente. Au fost stabilite următoarele criterii: tipul medicamentului asociat cu alcool etilic, vârsta pacienților, sexul, severitatea intoxicației, durata spitalizării, efectele toxice în asocierea alcool cu medicamente.

\section{Rezultate}

Astfel, în perioada de 5 ani menționată, au fost înregistrate 334 cazuri de intoxicaţii acute voluntare cu alcool etilic şi alcool etilic în asociere cu medicamente.

Din totalul de 334 cazuri, 33 intoxicații $(9,88 \%)$ au fost asocieri alcool etilic-medicamente.

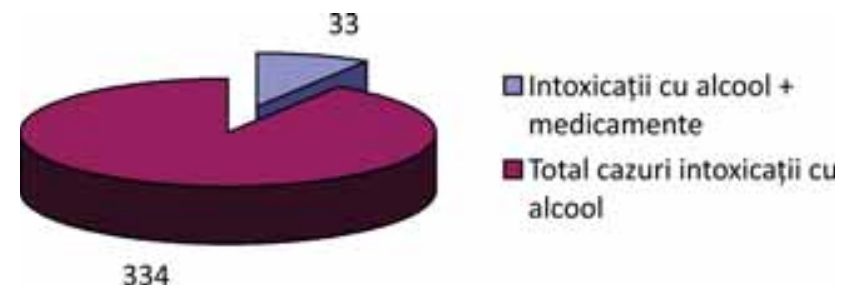

FIGURA 1. Prevalența asociației alcool etilicmedicamente

Din examenele toxicologice realizate, următoarele substanțe au fost implicate: barbiturice (16 cazuri), benzodiazepine ( 4 cazuri), dextrometorfan ( 3 cazuri), paracetamol (2 cazuri), disulfiram, canabinoizi (marijuana), carbamazepină, metronidazol,

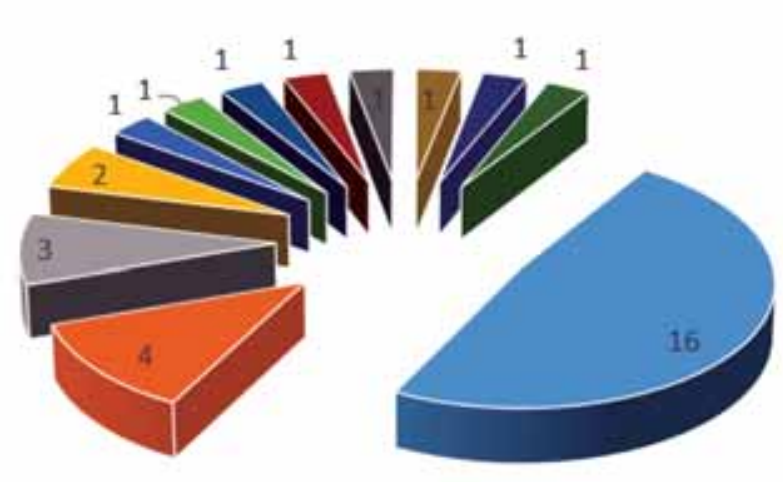

\footnotetext{
- Intoxicații cu alcool+barbiturice

- Intoxicatii cu alcool+benzodiazepine

- Intoxicații cu alcool+dextrometorfan

- Intoxicatii cu alcool+paracetamol

- Intoxicatii cu alcool+disulfiram

- Intoxicatii cu alcool+canabinoizi

- Intoxicatii cu alcool+carbamazepină

- Intoxicații cu alcool+metronidazol

- Intoxicații cu alcool+rifampicină

- Intoxicații cu alcool+nifedipină

- Intoxicatii cu alcool+doxepin

- Intoxicatii cu

alcool+dextrometorfan+diazepam
}

FIGURA 2. Tipuri de asocieri medicamentoase ale intoxicației acute cu alcool etilic 
rifampicină, nifedipină, doxepin şi dextrometorfan asociat cu diazepam (câte $1 \mathrm{caz}$ ).

Vârsta medie a pacienților a fost de 13,5 ani.

În toate cazurile, scorul de severitate a intoxicației (gradul de comă) a fost 2 sau 3, necesitând protezare respiratorie. Cele mai grave cazuri s-au regăsit în asocierea alcoolului etilic cu disulfiram, carbamazepină şi dextrometorfan.

Durata medie a spitalizării a fost de 2,4 zile în intoxicațiile cu asocieri, față de doar o zi în cele simple.

Benzodiazepinele, barbituricele, marijuana şi dextrometorfanul (25 cazuri) au fost folosite în combinație cu alcoolul ca droguri recreationale (pentru potențarea stării de euforie); în celelalte situații, alcoolul a fost utilizat pentru potențarea acțiunii toxice a medicamentelor, în scop suicidar (8 cazuri).

În sinteză, analiza datelor clinice în lotul analizat (33 cazuri) a revelat: bradipnee accentuată şi comă $($ PGCS $=8)$, necesitând protezare respiratorie (16 cazuri);
- etanol şi barbiturice - depresie respiratorie,

- etanol şi benzodiazepine - agitație, halucinații, hipotonie, comă ( 4 cazuri);

- etanol şi dextrometorfan - somnolență, vertij, distonie (4 cazuri);

- etanol şi marijuana - stare psihotică tranzitorie, euforie, halucinații, iluzii ( 2 cazuri);

- etanol şi carbamazepină, metronidazol, rifampicină, nifedipină, disulfiram etc. - intoxicații în scop suicidar.

\section{CONCLUZII}

- Asocierea alcool etilic - medicamente sau substanțe de abuz a fost întâlnită în 10\% dintre intoxicațiile grave cu alcool etilic la adolescenți.

- Benzodiazepinele, marijuana, barbituricele şi dextrometorfanul în asociere cu alcoolul etilic au fost folosite ca droguri de ,sevraj“, mai ales pentru potențarea stării de euforie.

- Asocierea alcool etilic - medicamente creşte severitatea intoxicației, profunzimea comei şi durata de spitalizare.

Conflict of interest: none declared Financial support: none declared

\section{BIBLIOGRAFIE}

1. Ulmeanu C.E., Niţescu V.G. Intoxicaţille acute cu alcooli în Intoxicaţiile acute la copil şi adolescent, Tridona, 2015.

2. Bailey B., Hantson P. Intoxication par les alcools et l'ethylene glycol în Lacroix J et. al: Urgences et soins intensifs pédiatriques - Approche clinique multidisciplinaire, Du Chu Sainte-Justine, 2012.
3. Wachter R.M., L. Goldman, Hollander H. (Eds.). Hospital medicine (2nd ed.), Lippincott Williams \& Wilkins, Philadelphia, 2005.

4. Voicu V.A. Toxicologie clinică, Albatros, București, 1997.

5. Baud F., Philippe Hantson P., Thabet H. Intoxications aiguës, Springer-Verlag France, Paris, 2013 